\title{
Histological evidence of initiating factors in acute necrotising pancreatitis in man
}

\author{
ALAN K FOULIS
}

From the University Department of Pathology, The Western Infirmary, Glasgow G11 6NT, UK

SUMMARY In this necropsy review of 37 cases of acute pancreatitis, evidence is presented that there are at least two different initiating mechanisms in acute necrotising pancreatitis in man. Firstly, there is primary duct inflammation, with subsequent inflammation and necrosis of the pancreatic parenchyma surrounding the excretory ducts. Included in this group are cases secondary to alcohol abuse and cholelithiasis. Secondly, there is necrosis confined to the microcirculatory periphery of the pancreatic lobule. These cases are usually secondary to some form of shock (septic or cardiogenic) and are thought to represent ischaemic pancreatitis. These patterns of necrosis are discussed in relation to the pancreatic anatomy and clinical findings.

The pathogenesis of acute pancreatitis in man remains an unsolved problem, and many different theories have been advanced. ${ }^{12}$ From a clinical standpoint most cases are associated with either gall stones or alcohol abuse, ${ }^{3}$ a few being secondary to viral infection, hyperparathyroidism, carcinoma, $^{3}$ or shock. ${ }^{4}$ The precise mechanism by which these cause acute inflammation in the pancreas is still a matter of considerable controversy.

In the relatively few detailed histological studies of unselected cases of acute pancreatitis, ${ }^{5-7}$ no attempt has been made to correlate the histological findings with the clinical associations of the disease. In the

Received for publication 6 May 1980 present histological study, two main anatomical patterns of pancreatic parenchymal necrosis have been observed, each of which suggests a different initiating mechanism. These patterns of necrosis have been correlated with the clinical and necropsy findings.

A brief description of the pancreatic microanatomy is included so that the significance of these patterns can be appreciated.

\section{Microanatomy of the pancreas (Fig. 1)}

Connective tissue septa divide the exocrine pancreas into secretory lobules, which are approximately $5 \mathrm{~mm}$ in diameter. Within the lobule the secretory

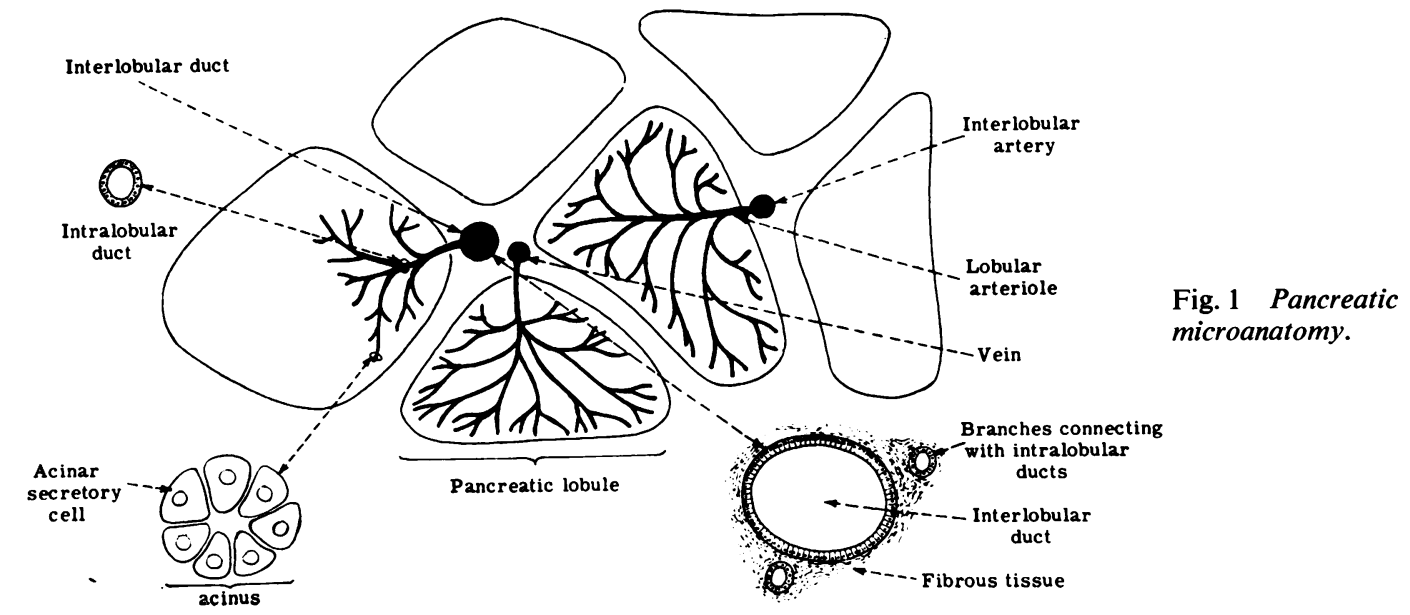


unit is the acinus. Secretion passes first into numerous branching intralobular ducts, which in turn join an interlobular duct running in the connective tissue septum. Both the intralobular and interlobular ducts are lined by low columnar epithelium, but there is more fibrous tissue in the wall of the latter. The interlobular ducts drain into the main pancreatic duct. ${ }^{8}$ No satisfactory work has been reported on the vascular supply of the pancreatic lobule in man. To date, studies have been confined to the rabbit and dog, ${ }^{910}$ in both of which the majority of lobules receive only one arterial branch. Thus in most lobules the lobular artery can be regarded as an end artery. The pattern of branching observed in the $\operatorname{dog}^{10}$ is such that in most lobules it is the periphery of the lobule, and in particular that part of the periphery opposite the entrance of the lobular artery, which is furthest from the main arterial source and thus most susceptible to ischaemia. The venous drainage closely follows the arterial supply.

\section{Material and methods}

The necropsy records of the Western Infirmary and Gartnavel General Hospital, Glasgow, over the last 10 years were studied, and consecutive cases of pancreatitis were selected on the basis of adequate histological material and a confirmed microscopic diagnosis. Details of the timing of diagnosis are given in Table 1. Material from 36 necropsies and from one surgical case of a subtotal pancreatectomy for acute haemorrhagic pancreatitis was judged suitable. The 37 patients comprised 21 men and 16 women with an age range of 40-89 years. In 19 cases only one paraffin block was available, and in all cases sections were stained by haematoxylin and eosin, Martius scarlet blue, Masson's trichrome, Gordon and Sweets' reticulin, periodic acid Schiff, PAS after diastase, and Gram stain for bacteria.

\section{Results}

\section{MACROSCOPIC APPEARANCES}

In four necropsies the pancreas was reported as normal; the rest were described as showing areas of necrosis or haemorrhage. Massive abdominal fat

Table 1 Diagnosis of pancreatitis

\begin{tabular}{|c|c|c|}
\hline Diagnosed clinically & $\begin{array}{l}\text { Pancreatitis presenting } \\
\text { complaint } \\
\text { Pancreatitis postoperative } \\
\text { complication }\end{array}$ & 10 \\
\hline Diagnosed at necrop & $\begin{array}{l}\text { Contributed significantly to } \\
\text { death } \\
\text { Encidental finding at necropsy }\end{array}$ & \\
\hline
\end{tabular}

necrosis was present in 13 cases, and in two a gall stone was found impacted at the ampulla of Vater.

MICROSCOPIC APPEARANCES

The following main patterns of necrosis were observed.

\section{Periductal necrosis (Figs 2 and 3)}

Necrosis of pancreatic parenchyma was confined to the immediate vicinity of intralobular or interlobular

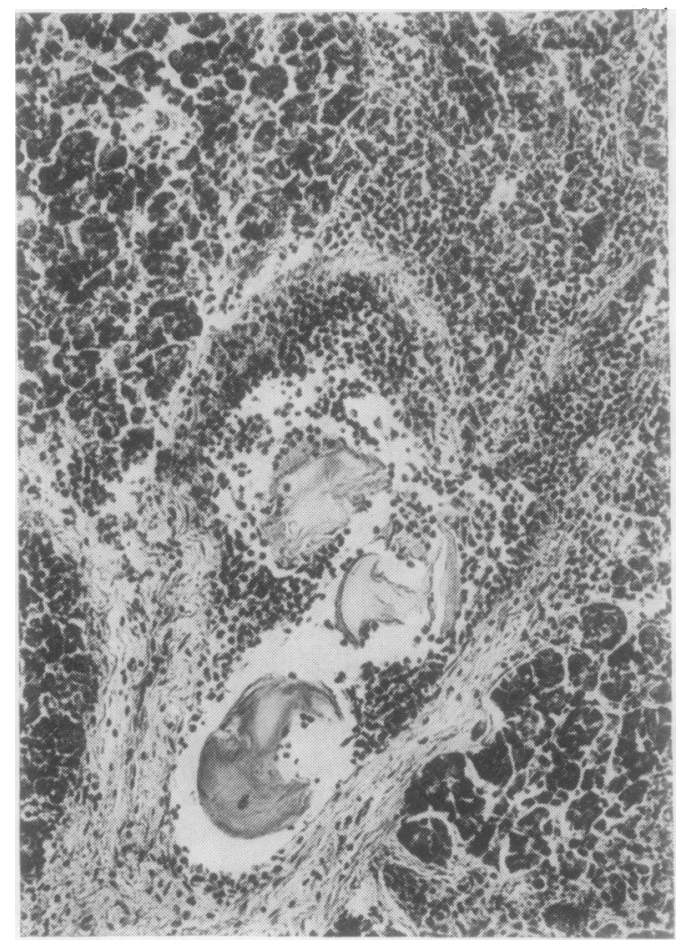

Fig. 2 Periductal necrosis related to an interlobular duct. Note that the concretions within the duct lumen are associated with a marked polymorph infiltrate. The inflammatory cells have extended through the duct wall into the surrounding exocrine pancreas, some of which is necrotic. (Haematoxylin and eosin $\times 100$ ).

ducts. In the majority of instances in which this pattern of necrosis was seen, polymorphs were found within the duct lumen, indicating the presence of duct inflammation (Table 2). Sometimes necrosis of the duct wall was seen, and in all cases there was a marked acute inflammatory infiltrate in the areas of pancreatic necrosis adjacent to the duct. Squamous metaplasia of duct epithelium was seen in only one case. There was a marked correlation, however, between the finding of duct inflammation and the 


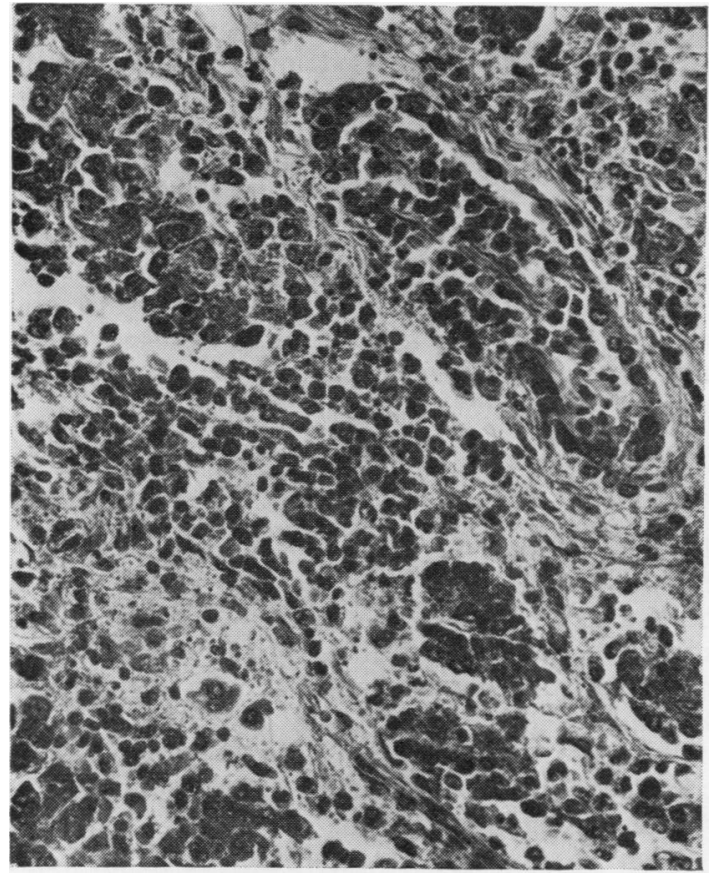

Fig. 3 A higher power view to show an inflamed interlobular duct with polymorphs again extending through the duct wall into an area in which there are necrotic pancreatic acini. (H and $E \times 290)$.
Table 2 Histological features associated with different patterns of necrosis in acute pancreatitis

\begin{tabular}{lcccc}
\hline $\begin{array}{l}\text { Pattern of } \\
\text { necrosis }\end{array}$ & No. & $\begin{array}{l}\text { Ducts } \\
\text { inflamed }\end{array}$ & $\begin{array}{l}\text { Venous } \\
\text { thrombosis }\end{array}$ & $\begin{array}{l}\text { Arterial } \\
\text { thrombosis }\end{array}$ \\
\hline $\begin{array}{l}\text { Periductal only } \\
\text { Perilobular only }\end{array}$ & 9 & 7 & 1 & - \\
$\begin{array}{l}\text { Periductal and } \\
\text { perilobular }\end{array}$ & 5 & 1 & 7 & 1 \\
$\begin{array}{l}\text { Panlobular only } \\
\text { Panlobular and }\end{array}$ & 8 & 4 & 3 & - \\
$\begin{array}{l}\text { periductal } \\
\begin{array}{l}\text { Panlobular and } \\
\text { perilobular }\end{array}\end{array}$ & 1 & 3 & 6 & 2 \\
$\begin{array}{l}\text { Unclassifiable } \\
\text { Total }\end{array}$ & 3 & 1 & 1 & - \\
\hline & 37 & 17 & 22 & - \\
\hline
\end{tabular}

presence of eosinophilic proteinaceous concretions within the duct lumen. In only two cases was inflammation found in the absence of such concretions. In spite of an intensive search no bacteria were observed in the lumens of inflamed ducts. In nine cases this was the sole pattern of necrosis that was found, and among these venous thrombosis was seen in only one.

\section{Perilobular necrosis (Fig. 4)}

Much of the periphery of the lobule was necrotic, but there was preservation of the centre. The boundary between necrotic and viable pancreas was marked by capillary thrombi and an acute inflammatory infiltrate. An interesting feature in this

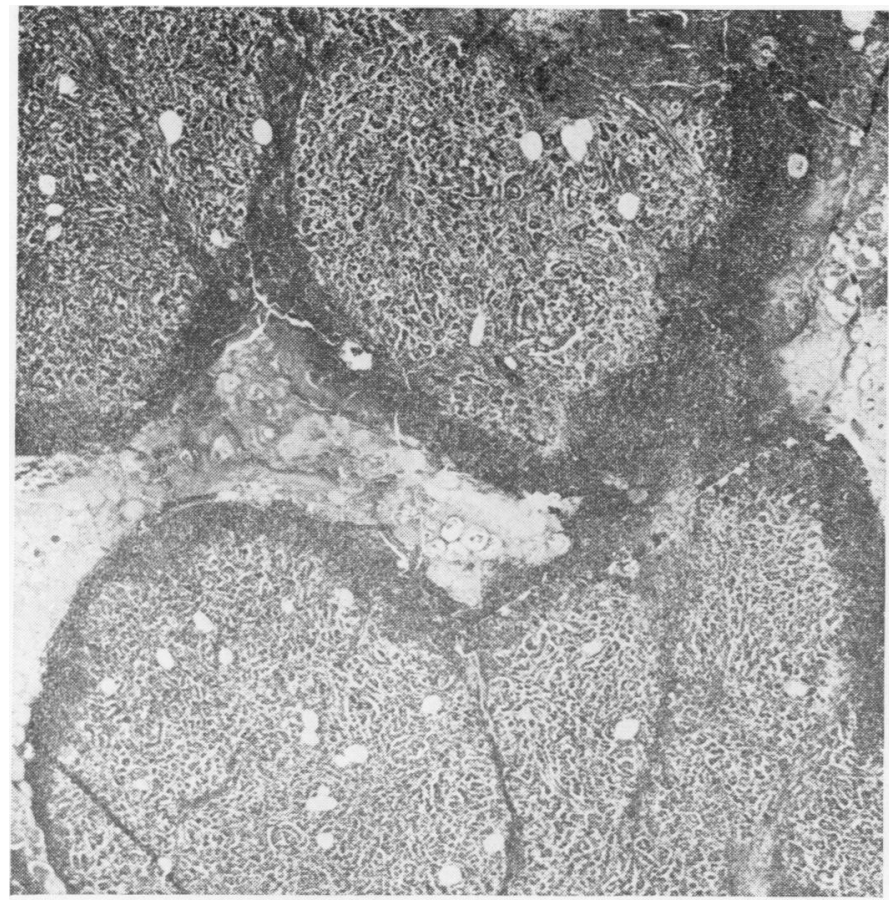

Fig. 4 Perilobular necrosis. Note that the pancreatic necrosis is confined solely to the periphery of the lobules. There is marked fat necrosis between adjacent lobules. (II and $E$ $\times 16)$. 
pattern of necrosis was that in sections where the entrance of a lobular artery into a lobule could be observed it was the periphery of the lobule opposite the entrance of the artery that was necrotic, and the part adjacent to the artery was normal (Fig. 5). In nine cases, this pattern of perilobular necrosis was the sole one seen. Among these, with one exception, duct inflammation was not observed, and even when ducts were found surrounded by necrotic debris there was no evidence of polymorphs within the duct lumen. Venous thrombosis was found in seven of these nine cases (Table 2).

In spite of the marked differences between these two patterns of necrosis, there were five cases where both were seen. This was not a result of sampling different parts of the pancreas since both patterns were seen in the same section. Among these, duct inflammation was found in four cases, and venous thrombosis in three.

\section{Panlobular necrosis}

There was confluent coagulative necrosis of entire lobules, including the intervening connective tissue septa, ducts, and blood vessels. A striking contrast between this pattern and the former two was the absence of inflammatory cells in much of the necrotic tissue. Where sections showed a clear boundary between necrotic and viable tissue thrombosed vessels could often be found in the area of necrosis (Fig. 6). Panlobular necrosis was observed in a total of 11 cases, and among these venous thrombosis was found in nine, and thrombosis of a large artery in two. In a further two cases, both perilobular necrosis and panlobular necrosis were seen. In one case there was periductal necrosis associated with duct inflammation in parts of the pancreas not involved by panlobular necrosis.

In three instances, although there was pancreatic necrosis, it appeared to be random in distribution, and no obvious anatomical pattern could be detected.

\section{OTHER MICROSCOPIC FEATURES}

\section{Vascular lesions}

Rich and Duff 5 described a vascular lesion found in both arteries and veins which they thought was specific for acute pancreatitis. The early changes were particularly striking in the media, with swelling and splitting of the muscle fibres and infiltration by polymorphs. In the advanced lesion there was complete necrosis of the media and sometimes actual rupture of vessels was found.

Such vascular lesions were observed in the veins in 17 of the 37 pancreases in the present study, and in six of these 17 arterial lesions were also found. Arterial lesions were not seen in the absence of venular inflammation.

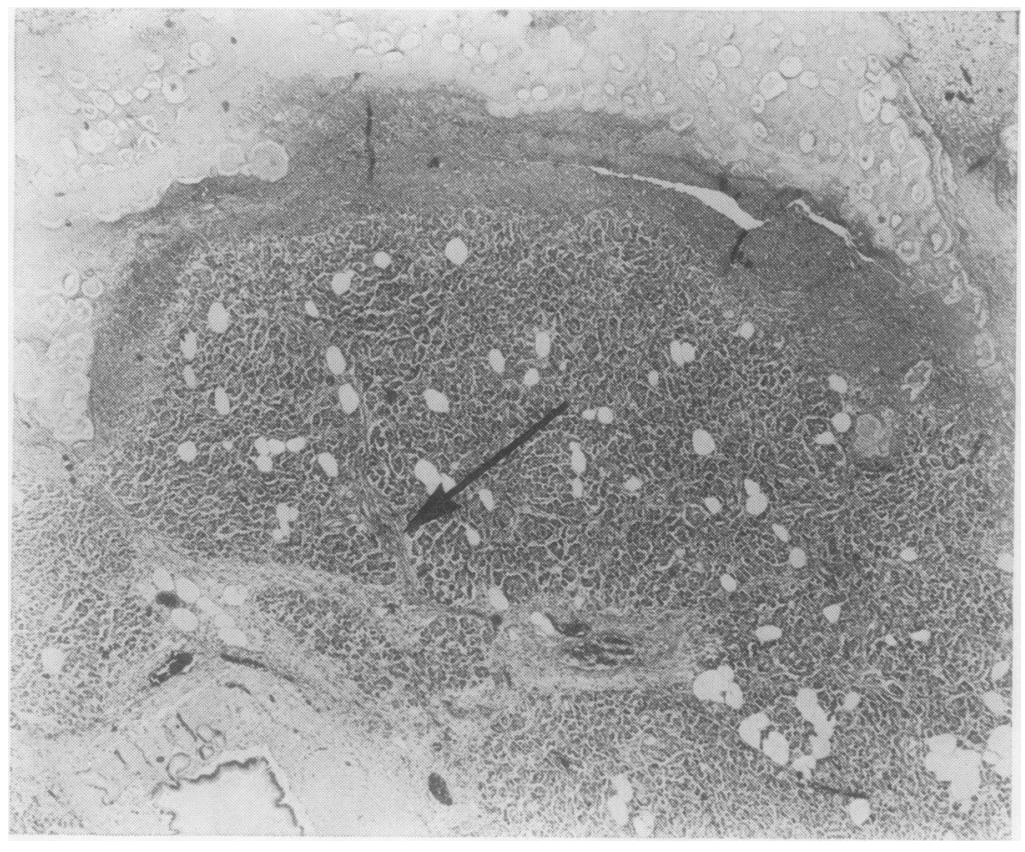

Fig. 5 In this lobule the perilobular necrosis is confined to that part of the periphery opposite the entrance of the lobular artery (arrowed). ( $H$ and $E \times 60)$ 


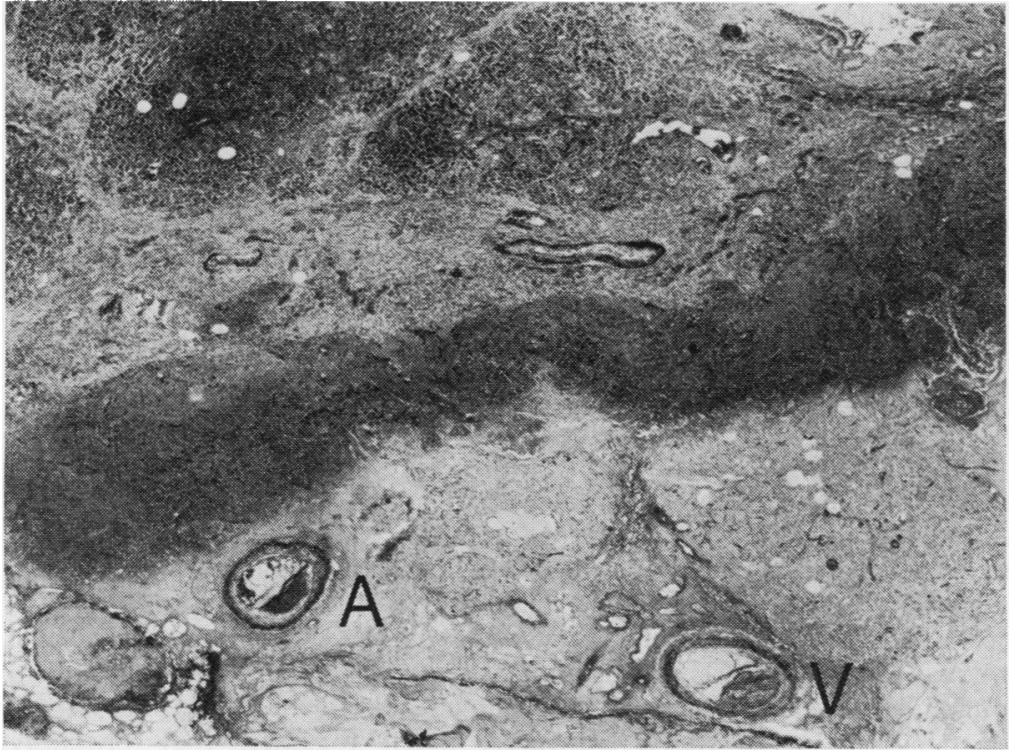

Fig. 6 This section demonstrates the sharp demarcation that of ten exists between viable pancreas and pancreas in which there is panlobular necrosis (seen here in the bottom half of the picture). Thrombosed veins $(V)$ and an artery $(A)$ are seen in the necrotic area. $(H$ and $E \times 16)$.

Venous thrombosis was seen in a total of 22. In 17 there was inflammation or necrosis of the vessel wall seen in relation to the thrombus, and in 11 thrombosis was seen in normal veins. In three there was thrombosis of a major artery. This was associated with an arteritis in two cases, and in the third the thrombosis was the result of surgical ligation of the splenic artery. Necrosis of arterial walls was seen in a total of six cases.

\section{Presence of bacteria}

In all sections a careful search was made for the presence of bacteria. These were observed histologically in areas of necrosis in four cases. In three, Gram-negative rods were seen, and in one, Gram-positive cocci. In one additional patient Escherichia coli was cultured from the pancreas at the laparotomy which confirmed the diagnosis of acute pancreatitis.

\section{Previous pancreatitis}

There was evidence of previous inflammation in 10 specimens. This comprised focal areas of fibrosis with destruction of lobules and dilatation of remaining acini. The changes were consistent with healing of previous exocrine inflammation by scar tissue.

\section{CLINICOPATHOLOGICAL CORRELATION}

The clinical findings were assessed retrospectively after the histological material had been studied. In Table 3 the clinical findings in patients with periductal necrosis are contrasted with those having perilobular necrosis. Perilobular necrosis was not
Table 3 Clinical association related to pattern of necrosis

\begin{tabular}{|c|c|c|c|}
\hline Periductal necrosis only & $\begin{array}{l}\text { No. of } \\
\text { cases }\end{array}$ & Perilobular necrosis only & $\begin{array}{l}\text { No. of } \\
\text { cases }\end{array}$ \\
\hline Alcohol abuse & 3 & Septic shock & 5 \\
\hline Cholelithiasis & 2 & Cardiogenic shock & 2 \\
\hline $\begin{array}{l}\text { Metastatic carcinoma in } \\
\text { pancreas }\end{array}$ & 1 & Postoperative & 1 \\
\hline Idiopathic & 3 & Idiopathic & 1 \\
\hline Total & 9 & & 9 \\
\hline
\end{tabular}

associated with either of the two common causes of pancreatitis: gall stones and alcohol abuse. In seven of the nine cases the clinical and necropsy evidence suggested that the pancreatitis was secondary to prolonged hypotension because of septic or cardiogenic shock. Further clinical details of these patients are given in the discussion section. By contrast, five of the nine patients with periductal necrosis were associated with alcohol abuse or gall stones. Among 11 patients with panlobular necrosis, gall stones were found at necropsy in five, and there was a history of alcoholism in three. Inevitably, in a retrospective review, there were a number of patients in whom the aetiology was uncertain, and four of the five patients with a mixed pattern of periductal and perilobular necrosis were included in this category. Gall stones were present in the fifth.

\section{Discussion}

Microscopy of the pancreas from a full blown clinical case of acute pancreatitis usually shows 
panlobular necrosis, and here the initiating lesion is probably obscured. Previous studies have concentrated on such cases. ${ }^{5-7}$ It is perhaps only when early or incidental pancreatitis is studied that the initiating lesion can be observed, and this has been attempted in the present study. As can be seen in Table 1, two-thirds of the cases had not been diagnosed clinically, and these included many early examples of acute pancreatitis.

There appear to be at least two sites of initial parenchymal necrosis in acute pancreatitis. In one, this is in the immediate vicinity of ducts, and in the second it occurs at the periphery of the lobule. What are the mechanisms involved in the production of these two patterns? There is a striking correlation between periductal necrosis and duct inflammation (Table 2). The mere presence of necrosis in the vicinity of the duct is not in itseif sufficient to cause duct inflammation since polymorphs are seldom seen in the duct lumen in sections showing panlobular necrosis. By contrast, primary duct inflammation can cause periductal necrosis. If pancreatitis is induced in a rabbit by a low-pressure intraduct infusion of $0.3 \mathrm{ml}$ of $E$. coli admixed with duodenal juice the initial lesion is severe duct inflammation. Sequential studies show that later there is necrosis of the duct wall, followed by periductal parenchymal necrosis (personal observation). Thus it seems likely that in cases with only periductal necrosis duct inflammation is the initial lesion.

The production of perilobular necrosis seems to have quite a different mechanism. Duct inflammation is seldom seen, and whereas venular thrombosis is rarely observed in cases with oniy periductal necrosis, it is commonly associated with perilobular necrosis. The necrosis is confined to the vulnerable microcirculatory periphery of the lobule, and here there is evidence of capillary thrombosis. Thus the histological findings support a primary ischaemic mechanism in this form of pancreatitis.

Although these two patterns appear to have distinct aetiologies they can be found together. A possible explanation of this is that the periductal necrosis may cause enzymatic damage to adjacent vessels, which then thrombose. It was shown by Rich and Duff ${ }^{5}$ that trypsin injected subcutaneously caused a vasculitis and thrombosis at the injection site. Vascular lesions similai to those that they attributed to trypsin attack were observed in three of the five cases with this mixed pattern of necrosis. Such thrombosis can obviously lead to sludging in the microcirculation and thus to perilobular necrosis.

Parlobular necrosis is the lesion commonly seen in very severe cases of haemorrhagic pancreatitis. The histological features of coagulative necrosis, littie evidence of inflammatory cell infiltrate within much of the necrotic tissue, and venular and occasionally arterial thrombosis at the junction between necrotic and viable tissue, all support the view of Thal et al. ${ }^{7}$ that these lesions represent infarcts. The likely mechanism here is destruction and thrombosis of blood vessels exposed to necrotic pancreatic parenchyma, with subsequent infarction, and so probably either of the initial forms of pancreatitis can progress to panlobular necrosis. The ischaemic nature of this lesion is supported by the work of Goodhead, ${ }^{11}$ who showed that in experimental pancreatitis the total pancreatic blood flow was raised initially, but later, with the onset of haemorrhagic pancreatitis, there was a profound drop in blood flow.

The distinction between the two early forms of pancreatitis would perhaps be of merely academic interest were it not for the fact that the clinical associations also showed striking differences(Table 3 ). This was an unexpected finding since the clinical details were obtained subsequent to the microscopic study. However, taken together, they probably underline the fundamental biological difference between these two forms of initial pancreatitis.

Histologically, periductal necrosis appears to be a 'duct-borne' disease in that the duct inflammation is probably primary. Cases associated with alcohol abuse and gall stones are included within this group, and there is evidence for a duct-related mechanism in both these clinical forms of pancreatitis. In 80 to $90 \%$ of patients with gall stone pancreatitis, migration of a gall stone from the common bile duct, through the ampulla, and into the duodenum apparently occurs during the attack of pancreatitis. ${ }^{12-14}$ In patients with a common channel, this will cause temporary pancreatic duct obstruction. Prolonged ingestion of alcohol leads to increased secretion of protein in the pancreatic juice with the formation of proteinaceous plugs, which can then cause obstruction. ${ }^{15}$ Thus in both alcohol- and gall stone-related pancreatitis there is evidence of duct obstruction, although the precise reason for the duct inflammation remains obscure.

In earlier clinical studies in Glasgow, gall stones or alcohol abuse were associated with acute pancreatitis in $83^{\circ}$ \% of cases. ${ }^{3}$ In the present study, no such association was present in the nine cases with only perilobular inecrosis. In two patients the diagnosis was cardiogenic shock secondary to acute myocardial infarction. A further five had septic shock, and in four of these the onset of shock was secondary to perforation of a viscus or leakage from an intestinal anastomosis. In these cases the pancreatitis appears to be secondary to the shock state. In the fifth case of septic shock, the pancreatitis may have been initiated by ligature of the splenic artery 
at a difficult splenectomy. The patient developed both pancreatitis and septic shock postoperatively. Necrosis confined to the periphery of the pancreatic lobule has been described by Feiner. ${ }^{16}$ She noticed that it was present in some patients who died after cardiac surgery and concluded that it was the result of diminished perfusion of the pancreas postoperatively. Thus both the histological distribution of the necrosis and the clinical state of the patients before death suggest that this represents a form of pancreatitis which is primarily ischaemic.

\section{Conclusion}

Histological and clinical evidence has been presented supporting the view that there are at least two different initiating mechanisms in acute pancreatitis. In one, there seems to be duct-borne disease in that duct inflammation appears to be the primary event. In the second, there is evidence that the initial lesion in the pancreas is the result of parenchymal ischaemia. Probably either of these can progress to a final common pathway of vascular damage, decreased pancreatic blood flow, and widespread pancreatic infarction, which is the hallmark of the advanced disease.

I am indebted to Mr Derek Bishop and Mr George McLaren for expert technical help.

\section{References}

${ }^{1}$ McCutcheon AD. A fresh approach to the pathogenesis of pancreatitis. Gut 1968;9:296-310.

${ }^{2}$ Creutzfeldt W, Schmidt H. Aetiology and pathogenesis of pancreatitis (current concepts). Scand J Gastroenterol Suppl. $1970 ; 6: 47-62$.
${ }^{3}$ Imrie CW, Benjamin IS, Ferguson JC, McKay AJ, MacKenzie I, O'Neill J, Blumgart LH. A single centre double-blind trial of Trasylol therapy in primary acute pancreatitis. Br J Surg 1978;65:337-41.

- Warshaw AL, O'Hara PJ. Susceptibility of the pancreas to ischaemic injury in shock. Ann Surg 1978;188:197-201.

${ }^{5}$ Rich AR, Duff GL. Experimental and pathological studies on the pathogenesis of acute haemorrhagic pancreatitis. Bull Johns Hopk Hosp 1936;58:212-58.

- Smyth CJ. Etiology of acute haemorrhagic pancreatitis with special reference to the vascular factors. Arch Pathol 1940;30:651-69.

7 Thal AP, Perry VF, Egner W. A clinical and morphological study of 42 cases of fatal acute pancreatitis. Surg Gynec Obst 1957;105:191-201.

8 Rhodin JAG. Histology. Oxford Medical Publications, $1973 ; 598$.

- Wharton GK. The blood supply of the pancreas with special reference to the islands of Langerhans. Anat Rec 1932;53:55-81.

${ }^{10}$ Cadete-Leite A. The arteries of the pancreas of the dog. An injection-corrosion and microangiographic study. Am J Anat 1973;137:151-8.

11 Goodhead B. Vascular factors in the pathogenesis of acute haemorrhagic pancreatitis. Ann $R$ Coll Surg Eng 1969; 45:80-97.

12 Acosta JM, Ledesma CL. Gall stone migration as a cause of acute pancreatitis. $N$ Engl J Med 1974;290:484-7.

${ }^{13}$ Kelly JR. Gallstone pancreatitis-pathophysiology. Surgery 1976;80:488-92.

14 Acosta JM, Rossi R, Galli OMB, Pellegrini CA, Skinner DB. Early surgery for acute gallstone pancreatitis. Evaluation of a systematic approach. Surgery 1978;83: 367-70.

${ }^{15}$ Sarles H, Sahel J. Pathology of chronic calcifying pancreatitis. Am J Gastroenterol 1976;66:117-39.

16 Feiner H. Pancreatitis after cardiac surgery: a morphologic study. Am J Surg 1976;131:684-8.

Requests for reprints to: $\operatorname{Dr}$ AK Foulis, University Department of Pathology, The Western Infirmary, Glasgow G11 6NT. 